visible only at 400 yards to a person with $6 / 6$ vision, that is, to anyone with $6 / 12$ vision at 200 yards or anyone with $6 / 9$ vision at 270 yards. There is no point in carrying the test any further, but we desire in concluding to recommend :-

1. The $6 / 6$ standard be adhered to for those concerned in the actual running of the train, guards, signalmen, drivers and firemen, whom we may, following the usual practice, call class $\mathrm{A}$.

2. For class $B$, that is, the remainder of the service, the standard already fixed provides for $6 / 12$ vision in the bad eye, and $6 / 6$ in the good; but it is a matter for your consideration whether spectacles might not be worn by class $\mathrm{B}$.

3. It is clearly desirable that the various semaphores should be elevated where it is possible against the sky-line, and that where that is impossible a suitable back-ground should in some way be provided. It is further desirable that they should be painted pure white throughout.

Summarising the results of the preceding tests-viz., on February 10th and February 12th. On February 10th, it was found that anyone possessing $6 / 6$ vision could accurately see the arm of the semaphore at 900 yards. With vision of $6 / 9$ that limit of visibility was reduced to 600 yards. On this occasion the atmosphere was smoky.

On February 12 the results varied somewhat owing to dust storms coming on at intervals; but, under the best circumstances, a man with $6 / 6$ vision could distinguish the arm of the semaphore at 1,300 yards, and with $6 / 9$ vision at 900 yards.

On both these occasions the background was uniform, but the conditions of the atmosphere varied.

\title{
ANNOTATIONS
}

\section{The Bowman Lecture, 1923}

After a personal appreciation of the invitation received by himself at Washington in 1922 to deliver the lecture, Dr. de Schweinitz paid tribute to the memory of Sir William Bowman, as well as to the Ophthalmological Society of the United Kingdom, of which he was the first President, and entered on his subject, premising that he was utilizing his own experience, and acknowledging his indebtedness to many colleagues in the U.S.A.

A very careful study of the anatomical relations of the pituitary body and adjacent structures opened the subject of the lecture. The practical part of this work had been carried out by Dr. J. Parsons Schaeffer, and the results were brought clearly before the meeting by the series of careful drawings which were exhibited, 
as obtained by examination of no fewer than 125 freshly exposed brains. It was proved that in 96 per cent. the optic chiasma is located wholly or in part over the diaphragma sellae, while in some cases the chiasma is found to be wholly behind the diaphragm; the vertical interval between the chiasma and the upper surface of the diaphragm varies from a potential cleft to a space as great as $10 \mathrm{~mm}$. The well known varieties in the shape of the sella Turcica were recapitulated, and it was pointed out that the infundibular stalk had a direction downwards and forwards, and that it was usually in contact with the chiasma. That the diaphragma sellae may vary from an almost complete tentorium to a mere marginal rim was confirmed. The arterial circle of Willis was next dealt with, and examples of abnormalities which would enable the anterior cerebral arteries to exert pressure on optic nerve, chiasma, or optic tract, were exhibited. How an abnormally large posterior communicating artery, sometimes passing direct into the posterior cerebral might be pressed against the optic tract by a pituitary growth, and thus give rise to homonymous hemianopia was indicated. The lecturer considered that neither pressure nor traction on the visual pathways by the tumour, was a satisfactory or complete explanation of the visual field defects in tumours of the hypophysis, and that, in particular, the scotomata were better explained on a toxic theory. He suggested that toxic products of the developing growth might be carried by the perivascular lymph channels to the subchiasmatic cisterna, and thence invade the visual fibres, of which it might be hypothecated that those of the macular bundle, being the most highly specialized, would be found to be the most vulnerable. The lecturer admitted that the nature of such toxins was unrecognized, but considered that some such hypothesis was necessary to explain the clinical manifestations and that his anatomical investigations disclosed the routes by which toxins might operate.

A historical survey of the discovered symptoms dealt with the visual defects and their development and progress both in the periphery and the centre of the fields of vision; and enabled Dr. de Schweinitz to discuss more fully their probable causation, and to review the variations and instability of the perimetric findings which frequently occur in gross pituitary body disorders.

The mimicry by pituitary disease of certain field defects due to other causes, such as toxic amblyopia, and sphenoidal sinus empyema was emphasized; that the latter disorder could involve the chiasma was shown to be possible in certain cases where a rather atypical anatomical relationship existed between the two structures. The possible association of hyper- and of hypo-pituitarism with central nerve disease, such as tabes, must not be overlooked in the analysis of a case, and tumours in the inter-peduncular space 
or springing directly from the chiasma might give rise to visual symptoms specially misleading by reason of secondary effects upon the hypophysis. The rapidity of onset of field defects, stationary periods after development, and the significance of temporary amaurosis were considered. Less importance was attached by the lecturer to defects in the colour fields than to those of the form sense, though observations in the one direction should be checked by, and correlated with, those in the other.

In Part 3, the importance of earlier diagnosis and treatment was dealt with. The types of pituitary headache were considered and a plea made for more consideration of this symptom. Fisher's suggestion that some cases now classed as migraine, may be attributable to intermittent swelling of the pituitary body was subjected to criticism but thought worthy of further deliberation.

In Part 4, attention was drawn to functional disorders of the pituitary body, particularly those now established to be almost constantly associated with pregnancy. Dr. de Schweinitz had confirmed the existence of temporal limitation of the fields of vision in the later months of pregnancy, the fields being restored after confinement, but was of opinion that central scotomata and enlargement of the blind spot could not be demonstrated; he argued from this in favour of the toxic influence of the products of the diseased pituitary body, but that the pituitary body, physiologically enlarged during pregnancy, was little likely to produce a harmful secretion, though the mechanical effects would be identical whatever the cause of the enlargement and proportioned only to the bulk of the swelling. Repeated pregnancies were sometimes followed by symptoms of dyspituitarism, due to persistence and extension of changes in the hypophysis initiated by the pregnancies. After double oophorectomy, field changes similar to those associated with pregnancy were found, but were permanent; hyperplasia of the pituitary body was suggested-but more investigation in this direction was desirable.

Attention was pointed to transitory pituitary body symptoms during menstruation, mainly hemianopic and scintillating scotomata, and to those of headache, rapid growth and deposit of fat at puberty; pituitary body feeding was of much value in such cases at adolescence.

In Part 5, the question of toxic effects following influenza or the drinking of methyl alcohol upon the pituitary body was reviewed; experiments by the lecturer upon dogs with methyl alcohol had been fruitful, mainly in the direction of negative results.

In Part 6, the lecturer dealt with Leber's disease, and the theory put forward by Fisher that hereditary tendency to over activity of the pituitary body at puberty or climacteric best explained this interesting form of optic atrophy. The fact that change in the 
sella Turcica demonstrable by X-rays was the exception and not the rule in these cases was no argument against the truth of the theory. Dr. de Schweinitz was inclined to suggest as a supplement to Fisher's view his own conception of the transference of toxins from the hypophysis to the chiasma.

In Part $\tau$, the appearance of the discs was pointed out, the best methods of the radiologist were indicated; the significance of the various deformations of the sella Turcica was discussed-surgical treatment was a subject outside the sphere of the lecture--but the methods and value of organotherapy were reviewed, as well as the effects of X-rays and radium, particularly when used subsequent to operation.

A complete bibliography of the whole subject is appended to the lecture, and cannot fail to be of the greatest assistance.

It is impossible to do justice to so valuable and so interesting a lecture in the space at our disposal, and especially in the absence of the drawings, fields and diagrams with which it is illustrated. Above all the absence of the magnetic personality of the lecturer is a defect for which there can be no compensation.

\section{The Aetiology of Miners' Nystagmus}

Every reader will recall the first Report of the Miners' Nistagmus Committee which was published last year. After a fuil and impartial discussion the Committee concluded that defective illumination was the essential factor in the causation of the disease. Other factors, such as position, alcoholism, hereditary predisposition, errors of refraction were considered to be merely of secondary importance. These views, reached after a careful review of the subject, have been generally adopted. Dr. A. S. Percival, however, (British Medical Journal, May 5 and June 9, 1923), considers, as did the late Simeon Snell, that the primary factor is to be found in the constrained position of the eyes assumed by coal-hewers. He bases his views upon figures obtained from thirty-two pits in the counties of Northumberland and Durham. Of 36,232 men employed by these mines 11,383 were hewers and 24,849 were nonhewers. One hundred and three of the former and fifty-nine of the others acquired nystagmus, in other words, the percentage of hewers with nystagmus was 0.949 , and of the others 0.2374 . A new theory has also been developed by Dr. Frederick Robson in two papers recently read by him before the South Wales Institute of Engineers. Briefly, Robson believes that the chief cause of miners' nystagmus is the emanations of noxious gases from coal which has been recently cut. He particularly specifies carbon monoxide in this connection. He points out that, in the South Wales and Monmouthshire coal field there is a progressive diminution in the 